\title{
Optimum allocation of multi-items in stratified random sampling using principal component analysis
}

\author{
Apantaku Fadeke Sola. ${ }^{1}$, Olayiwola Olaniyi Mathew ${ }^{1}$, Adewara Amos Adedayo ${ }^{2}$ \\ ${ }^{1}$ Department of Statistics, Federal University of Agriculture, Abeokuta, Ogun State, Nigeria \\ ${ }^{2}$ Department of Statistics, University of Ilorin, Nigeria
}

\section{Email address:}

laniyimathew@yahoo.com(O.M. Olayiwola)

\section{To cite this article:}

Apantaku Fadeke Sola., Olayiwola Olaniyi Mathew, Adewara Amos Adedayo. Optimum Allocation of Multi-Items in Stratified Random Sampling Using Principal Component Analysis. American Journal of Theoretical and Applied Statistics. Vol. 2, No. 5, 2013 , pp. $142-148$. doi: $10.11648 /$ j.ajtas.20130205.14

\begin{abstract}
The problem of allocation with more than one characteristic in stratified sampling is conflicting in nature, as the best allocation for one characteristic will not in general be best for others. Some compromise must be reached to obtain an allocation that is efficient for all characteristics. In this study, the allocation of a sample to strata which minimizes cost of investigation, subject to a given condition about the sampling error was considered. The data on four socioeconomic characteristics of 400 heads of households in Abeokuta South and Ijebu North Local Government Areas (LGAs) of Ogun State, Nigeria were investigated. These comprised of 200 households from each LGA. The characteristics were occupation, income, household size and educational level. Optimal allocation in multi-item was developed as a multivariate optimization problem by finding the principal components. This was done by determining the overall linear combinations that concentrates the variability into few variables. From the principal component analysis, it was seen that for both Abeokuta and Ijebu data sets, the variance based on the four characteristics as multivariate is less than that of the variables when considered as a univariate. From the results, it was seen that there was no difference in the percentage of the total variance accounted for by the different components from the merged sample when compared with the individual sample. Optimum allocation was achieved when there was stratification
\end{abstract}

Keywords: Stratified Sampling, Optimum Allocation, Stratification, Optimization

\section{Introduction}

In social research, special emphasis is placed on the comparative and analytical use of samples. Knowledge, attitudes, and actions in everyday life are based to a very large extent on samples (Cheang, 2011; Cochran, 1977). In survey, samples are used instead of population and most of these samples are prepared by Statisticians and one of the areas of Statistics that is most commonly used in all fields of scientific investigation is that of probabilistic sampling. Surveys used by social scientists are based on complex sampling designs (Lumley, 2004; Winship and Radbill, 1994).

One of the main problems in sampling survey is the optimal allocation of resources. Usually, the solution of this problem is rather arbitrary due to the fact that no best allocation is defined. In this study, the allocation of a sample to strata which minimizes cost of investigation, subject to a given condition about the sampling error was considered.

\section{The Data}

The data on four socioeconomic characteristics of 400 heads of households in Abeokuta South and Ijebu North Local Government Areas (LGAs) of Ogun State, Nigeria were investigated. These comprised of 200 households from each LGA. The characteristics were occupation, income, household size and educational level.

\section{Methodology}

\subsection{Introduction}

The procedure for estimation from multiple frames was given by Hartley (1962, 1964). According to Hartley, choosing a simple cost function provides rules for optimal choices of subject to a given value. Saxens et al. (1986) considered the extension of Hartley's procedure to the case of two stage sampling of the multi-stage sampling. They 
worked out optimal choices of the variable of interest considering suitable cost functions and recommended replacement of unknown parameters occurring in the optimal solutions by sample analogues. Hence the problem of small domain statistics and a special method of estimation is needed for the parameters relating to small domains. Bankier (1996) discussed a few issues involved in small area or local area estimation. The problem is how to estimate the domain. These estimators make a minimal use of data that may be available. To improve upon the estimators, the database is broadened and strengths are borrowed from data available on similar domains and secondary external sources. According to Bankier (1996), post-stratified estimators of auxiliary data, is to be used. These post strata may stand for age, sex, or ethnic groups in usual practices.

\subsection{The Multivariate Optimum Allocation}

The problem of allocating sample to various strata may be viewed as minimizing the variances of various characters subject to the conditions of the given budget and tolerance limits on certain variances. The problem turns out to be nonlinear programming problem with several linear objective functions and single convex constraint. Pizada and Maqbool (2003), solved the resulting linear programming problem through Chebyshev approximation. The criteria behind the Chebyshev approximation are to find a solution that minimizes the single worst. Suppose that $p$-characteristics are measured on each unit of a population which is partitioned into $L$ strata. Let $n_{i}$, be the number of units drawn from the ith stratum $(i=1,2, \ldots . ., L)$. For the $j t h$ character an unbiased estimate of the population mean, $\bar{Y}_{j}$, is $\bar{y}_{j s t}$ which has the sampling variance.

$$
\operatorname{Var}\left(\bar{y}_{j s t}\right)=\sum_{i=1}^{L} W_{i}^{2} S_{i j}^{2} X_{i} \quad j=1,2, \ldots, p
$$

where $W_{i}=\frac{N_{i}}{N}, S_{i j}^{2}=\frac{1}{N_{i}-1} \sum_{h=1}^{N_{i}}\left(y_{i j t h}-\bar{y}_{i j}\right)^{2}$ and $X_{i}=\frac{1}{n_{i}}-\frac{1}{N_{i}}, a_{i j}=W_{i}^{2} S_{i j}^{2}$, in usual notation.

Let $c_{i j}$ be the cost of enumerating the $j t h$ characteristic in the ith stratum and let $k$ be the upper limit on total cost of the survey. Then

$$
\sum_{i=1}^{L} \sum_{j=1}^{p} c_{i j} n_{i} \leq k
$$

The multivariate allocation problem can be stated as

$$
\text { Minimize } \quad z_{j}=\sum_{i=1}^{L} a_{i j} X_{i}-\sum_{i=1}^{L} \frac{a_{i j}}{N_{i}}, \quad j=1,2, \ldots ., p
$$

Subject to

$$
\sum_{i=1}^{L} \sum_{j=1}^{p} \frac{c_{i j}}{X_{i}} \leq k
$$

$$
\frac{1}{N_{i}} \leq X_{i} \leq 1, \quad i=1,2, \ldots \ldots, L
$$

where $\frac{1}{X_{i}}$ is used for $n_{i}$. If (3) is considered separately for each character, by ignoring the constant term in the objective function, the problem for $k$ th character becomes

Minimize

$$
Z_{k}=\sum_{i=1}^{L} \frac{a_{i k}}{X_{i}}
$$

Subject to

$$
\sum_{i=1}^{L} \sum_{j=1}^{p} c_{i j} X_{i} \leq k
$$

$1 \leq X_{i} \leq N_{i}, \quad i=1,2, \ldots \ldots \ldots, L$.

By introducing a new variable $x_{L+k}$, the problem (4) transforms to

$$
\text { Minimize } \quad Z_{k}=x_{L+k}
$$

Subject to

$$
\begin{aligned}
g_{k}(X)= & \sum_{i=1}^{L} \frac{a_{i k}}{X_{i}}-X_{L+k} \leq 0 \quad \text { (b) } \\
& \sum_{i=1}^{L} \sum_{j=1}^{p} c_{i j} X_{i} \leq k \\
& 1 \leq X_{i} \leq N_{i}, \quad i=1,2, \ldots . L .
\end{aligned}
$$

The constraints in (5b) are convex (Kokan and Khan, $1967)$ and the constraint $(5 c)$ and the bounds (5d) are linear. The problem (5a)- $(5 d)$ is therefore a convex programming problem with linear objective and can be solved by using any method of convex programming. The Chebyshev approximation formulation of the multiple objective allocation problems in (5) is the following linear programming problem (LPP):

Minimize $\delta$

Subject to

$$
\begin{aligned}
& 2 \sum_{i=1}^{L} \frac{a_{i k}}{X_{i}^{k(0)}}-\sum_{i=1}^{L} \frac{a_{i k} X_{i}}{X_{i}^{k(0)^{2}}}-X_{L+k} \leq 0 \\
& \sum_{i=1}^{L} \sum_{j=1}^{p} c_{i j} X_{i} \leq k \quad l=1,2, \ldots \ldots, t_{k} \\
& k=1,2, \ldots \ldots, p \\
& X_{L+k}-\delta \leq z_{k}^{0} \\
& 1 \leq X_{i} \leq N_{i} \quad i=1,2, \ldots \ldots, L
\end{aligned}
$$

The $p$ solutions $X_{1}^{0}, X_{2}^{0}, \ldots, X_{p}^{0}$ have been obtained by minimizing the individual objective functions subject to the linearized constraints by letting the minimum values of $Z_{k}$ 
to be found as $Z_{k}^{0}, k=1,2, \ldots, p$ at the corresponding minimal points $X_{k}^{0}, k=1,2, \ldots, p$. This gives the aspiration levels being used in Chebyshev approximation.

Formally the problem of optimum allocation in stratified sampling can be presented as a multi-objective, nonlinear optimization as

$$
\min \hat{\operatorname{Var}}\left(\bar{y}_{s t}\right)=\min _{n}\left(\begin{array}{c}
\hat{\operatorname{Var}}\left(\bar{y}_{s t}^{1}\right) \\
: \\
\vdots \\
\hat{\operatorname{Var}}\left(\bar{y}_{s t}^{G}\right)
\end{array}\right)
$$

Subject to

$$
c^{\prime} n+c_{0}=C
$$

Where $\mathrm{C}$ is the total cost, $c_{0}$ is the fixed cost and $c^{\prime}=\left(c_{1}, \ldots \ldots . . c_{H}\right)$ and $n^{\prime}=\left(n_{1}, n_{2}, \ldots \ldots \ldots n_{H}\right)$

The solutions in (7) take real values and the sample sizes $n_{h}$ must be integers. There is the problem of estimating the variance on the basis of the sample size in each stratum and also the problem of over sampling, that is, when $n_{h} \geq N_{h}$ for at least some $h$.

An alternative to (7), is given as

$$
\min \hat{\operatorname{Var}}\left(\bar{y}_{s t}\right)=\min _{n}\left(\begin{array}{c}
\hat{\operatorname{Var}}\left(\bar{y}_{s t}^{1}\right) \\
\vdots \\
\vdots \\
\hat{\operatorname{Var}}\left(\bar{y}_{s t}^{G}\right)
\end{array}\right)
$$

where $\mathrm{G}$ is number of characterristics

$$
\text { subject to }
$$

$$
\begin{aligned}
& c^{\prime} n+c_{0}=C \\
& 2 \leq n_{h} \leq N_{h}, h=1,2, \ldots \ldots, H \\
& n_{h} \in \mathrm{N}
\end{aligned}
$$

Where $\mathrm{N}$ denotes the set of natural numbers. The methods for resolving a multi-objective optimization programme can be classified by considering the amount of information possessed concerning the study population, with three different scenarios, namely complete, partial or zero information (Steuer, 1986; Miettinen, 1999; DiazGarcia and Ulloa, 2006). Diaz-Garcia and Ulloa (2006) consider problem (3.79) from the stand-point of the multiobjective optimization methods by using complete information such as value function and lexicographic, partial information method such as $\mathcal{E}$-constraint and also zero information such as the distances.

\subsection{Optimum Allocation via Multi-objective Optimization}

The estimator of the population mean in multivariate stratified sampling for the $j t h$ characteristic is defined as

$$
\bar{y}_{s t}^{j}=\sum_{h=1}^{H} W_{h} \bar{y}_{h}^{j}
$$

Where $\bar{y}_{h}^{j}=\frac{1}{n_{h}} \sum_{h=1}^{n_{h}} y_{h i}^{j}$ is the sample mean in stratum $h$ of the $j$ th characteristic, and $y_{h i}^{j}$ is the value obtained for the $i$-th unit in stratum $h$ of the $j$-th characteristic. The $\operatorname{Var}\left(\bar{y}_{s t}^{j}\right)$ is defined using the population variances $S_{h}^{2}, h=1,2, \ldots \ldots ., H$, which are usually unknown, and therefore these are substituted by the sample variances $s_{h}^{2}, h=1,2, \ldots . ., H$, defined as

$$
s_{h}^{2}=\frac{1}{n_{h}-1} \sum_{i=1}^{n_{h}}\left(y_{h i}-\bar{y}_{h}\right)^{2}
$$

And thus $\hat{\operatorname{Var}}\left(\bar{y}_{s t}^{j}\right)$ is substituted by the estimated variance $\hat{\operatorname{Var}}\left(\bar{y}_{s t}^{j}\right)$, which is given by

$$
\hat{\operatorname{Var}}\left(\bar{y}_{s t}^{j}\right)=\sum_{h=1}^{H} \frac{W_{h}^{2} s_{h j}^{2}}{n_{h}}-\sum_{h=1}^{H} \frac{W_{h} s_{h j}^{2}}{N}
$$

\subsection{Value Function}

Under the value function technique, programme (8) is expressed as

$$
\begin{aligned}
& \min _{\mathrm{n}} v\left(\hat{\operatorname{Var}}\left(\bar{y}_{s t}\right)\right) \\
& \text { subject to } \\
& 2 \leq n_{h} \leq N_{h} \quad h=1,2, \ldots \ldots ., H \\
& \quad n_{h} \in N
\end{aligned}
$$

Where $v(\cdot)$ is a scalar function that summarizes the importance of each of the variances of the $\mathrm{G}$ characteristics. Evidently for every problem the value function $v(\cdot)$ may take an infinite number of forms and this constitutes the difficulty for the evaluator in defining such a function. Some simple functions have given excellent results in applications and one of these particular forms is the weighting method. Under the weighting approach, (12) can be expressed as

$$
\begin{aligned}
& \min _{n} \sum_{j=1}^{G} \lambda_{j} \hat{\operatorname{Var}}\left(\bar{y}_{s t}^{j}\right) \\
& \text { subject to } \\
& \sum_{h=1}^{H} c_{h} n_{h}+c_{0}=C \\
& 2 \leq n_{h} \leq N_{h}, \quad h=1,2, \ldots \ldots, H \\
& \quad n_{h} \in N
\end{aligned}
$$

Such that

$$
\sum_{j=1}^{G} \lambda_{j}=1, \quad \lambda_{j} \geq 0 \forall j=1,2, \ldots ., G ; \text { where } \lambda_{j}
$$


weighs the importance of each characteristic. In the context of multi-objective optimization, (13) is without doubt the method that has been mostly thoroughly studied. Its popularity is due to the fact that the value function is unique. The value function method is utilized for recurrent studies in which over time, the results obtained using (13) help in reaching a better inference for future experiments, in which the appropriate weighting can be applied.

\subsection{Optimal Design for a Multivariate Stratified Sampling Adopted in this Study}

The idea of optimal allocation under a multivariate stratified sampling in this study is based on an alternative approach as in Diaz-Garcia and Ramos-Quiroga (2011).

The linear programming problem is assumed to be $\min _{n} \theta$

Subject to

$$
\begin{aligned}
& \sum_{h=1}^{H} C_{h} n_{h}+C_{0}=C \\
& 2 \leq n_{h} \leq N_{h}
\end{aligned}
$$

Where $\theta=\operatorname{Cov}\left(\bar{y}_{s t}\right)$. This is the matrix of variance covariances of the vector

$\tilde{\mathrm{y}}_{\mathrm{st}}=\left(\tilde{\mathrm{y}}_{\mathrm{st}}\right.$, $\left.\tilde{y}_{\text {st }}\right)$.

the sub index $\mathrm{h}=1,2, \ldots . \mathrm{H}$ denotes the stratum $\mathrm{i}=$ $1,2, \ldots . . N_{h}$ or $n_{h}$ within stratum $h$ and $j=1,2, \ldots ., G$. denotes the characteristic (variable).

The covariance matrix of $\tilde{y}_{\text {st }}$ denoted as $\operatorname{cov}\left(\tilde{y}_{\mathrm{st}}\right)$ is defined in matrix

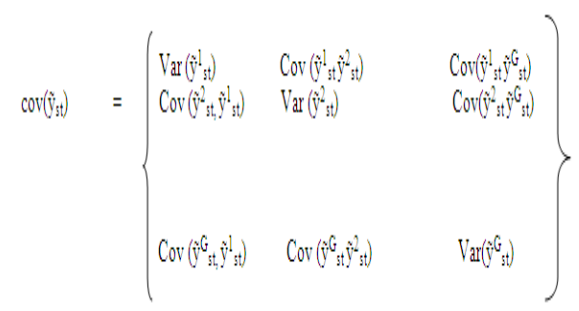

and the estimated covariance of $\tilde{y}_{s t}^{i}$ and $\tilde{y}_{s t}^{j}$ as $\operatorname{Cov}\left(\tilde{y}_{s t}^{i}\right.$ and $\tilde{y}_{\text {st }}^{j}$ ).

This $\operatorname{Cov}\left(\tilde{y}_{s t}^{i}\right.$ and $\left.\tilde{y}_{s t}^{j}\right)=\operatorname{Cov}\left(\tilde{y}_{s t}^{j}\right.$ and $\left.\tilde{y}_{s t}^{i}\right)$

$$
\begin{aligned}
& \operatorname{Cov}\left(\tilde{\mathrm{y}}_{\mathrm{st}}^{\mathrm{i}}, \tilde{\mathrm{y}}_{\mathrm{st}}^{\mathrm{j}}\right)=\sum_{h=1}^{H} \frac{w_{h}^{2} s_{h i}}{n_{h}}-\sum_{h=1}^{H} \frac{w_{h} s_{h i j}}{N}
\end{aligned}
$$

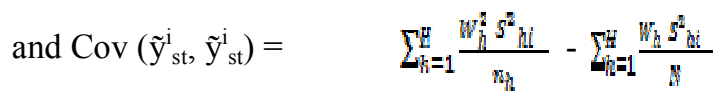

and $C_{h}$ is the cost per $\mathrm{G}$ - dimensional sampling unit in stratum $h$ and its vector

$$
\mathrm{C}=\left(\mathrm{C}_{1}, \ldots \ldots \ldots \mathrm{C}_{\mathrm{G}}\right)^{1} \text {. }
$$

\subsection{Principal Component Analysis}

Optimal allocation in multi-item is developed as a multivariate optimization problem by finding the principal components. This was done by determining the overall linear combinations that concentrates the variability into few variables. We then search for a set of mutually uncorrelated variables, $Y_{1}, Y_{2}, \ldots ., Y_{p}$ each one being a linear combination of the original set of variables, $X_{1}, X_{2}, \ldots . ., X_{p}$. One of the motivations for determining such a collection is in of, if we derive a set that concentrates the overall variability into the first few variables, it is perhaps easier to see what accounts for the variation in the data.

Indeed, if a few of the $\left\{Y_{i}\right\}$ seem to account for most of the variation in the data, then it could be argued that the effective dimensionality is less than $\mathrm{P}$ and this could result in a simplified analysis based on a smaller set of variables (Khan and Ahsan, 2003; Garcia and Cortez, 2006).

\subsection{Finding Principal Components}

Suppose that $X=\left(X_{1}, X_{2}, \ldots \ldots, X_{p}\right)^{\prime}$ is a random vector with mean $\mu$ and covariance matrix $\Sigma$. Then the principal components of $X$, defined by $Y_{1}, Y_{2}, \ldots \ldots, Y_{p}$ satisfies the following conditions:

i. $Y_{1}, Y_{2}, \ldots \ldots, Y_{p}$ are mutually uncorrelated.

ii. $\operatorname{Var}\left(Y_{1}\right) \geq \operatorname{Var}\left(Y_{2}\right) \geq \ldots \ldots \ldots \geq \operatorname{Var}\left(Y_{p}\right)$.

iii. $Y_{j}=a_{1 j} X_{1}+a_{2 j} X_{2}+\ldots \ldots .+a_{p j} X_{p}=a_{j}^{\prime} X$.

where $a_{j}=\left(a_{1 j}, a_{2 j}, \ldots . ., a_{p j}\right)^{\prime}$ is a vector of constants satisfying

$$
\begin{aligned}
\left\|a_{j}\right\|^{2} & =a_{j}^{\prime} a_{j} \\
& =\sum_{k=1}^{p} a_{k j}^{2} \\
& =1 \quad \text { for all } j=1,2, \ldots \ldots, p .
\end{aligned}
$$

In addition, the $\mathrm{j}^{\text {th }}$ principal component

$Y_{j}=a_{j}^{\prime} X$

is the linear compound of $X$ that maximizes $\operatorname{Var}\left(Y_{j}\right)$, subject to being uncorrelated with the preceding components $Y_{1}, Y_{2}, \ldots \ldots \ldots . Y_{j-1}$.

Since $Y_{j}=a^{\prime} X$ is a linear compound, then

$$
\begin{aligned}
\operatorname{Var}\left(Y_{j}\right) & =\operatorname{Var}\left(a_{j}^{\prime} X\right) \\
& =a_{j}^{\prime} \Sigma a_{j} \quad j=1,2, \ldots \ldots ., p
\end{aligned}
$$

To derive the first principal component of $Y_{1}$, we have

$$
\operatorname{Var}\left(Y_{1}\right)=a_{1}^{\prime} \Sigma a_{1}
$$

The idea is to select $a_{1}$ in such a way that $\operatorname{Var}\left(Y_{1}\right)$ is as large as possible, subject to the constraint $a_{1}^{\prime} a_{1}=1$ 
This is a standard problem in constrained optimization and may be solved using the method of LaGrange multipliers.

To use this method the LaGrangian is formed as

$$
L_{1}(a)=a^{\prime} \Sigma a-\delta\left(a^{\prime} a-1\right)
$$

The required $a_{1}$ is the value of $a$ that is a stationary point of (13).

Now define

$$
\nabla a(\bullet)=\left(\frac{\partial}{\partial a_{1}}, \frac{\partial}{\partial a_{2}}, \ldots \ldots \ldots \ldots . . ., \frac{\partial}{\partial a_{p}}\right)^{\prime}
$$

It may be shown that

$$
\begin{aligned}
& \nabla a\left(a^{\prime} \Sigma a\right)=2 \Sigma a \\
& \nabla a\left(a^{\prime} a\right)=2 a
\end{aligned}
$$

A stationary point of (3.122) must satisfy:

$$
\nabla a\left(L_{1}(a)\right)=0
$$

Since

$$
\begin{aligned}
\nabla a\left(L_{1}(a)\right) & =\nabla a\left(a^{\prime} \Sigma a\right)-\delta \nabla a\left(a^{\prime} a-1\right) \\
& =2 \Sigma a-2 \delta a
\end{aligned}
$$

It follows that $\mathrm{a}_{1}$ satisfies

$$
2 \Sigma a_{1}-2 \delta a_{1}=0
$$

That is,

$$
(\Sigma-\delta \mathrm{I}) a_{1}=0
$$

A non-trivial solution $\left(a_{1} \neq 0\right)$ to the above exists if, and only if

$$
|\Sigma-\delta \mathbf{I}|=0
$$

Where $|\bullet|$ is the determinant operator.

Thus $\delta$ must be an Eigen value of $\sum$, with $a_{1}$ being its corresponding Eigen vector:

Since $\sum$ is a $p \times p$ symmetric matrix, then there can be up to $p$ distinct Eigen values. Since $\sum$ is positive (semi) definite, then all of its Eigen values are non-negative.

Assume, for the moment, that the Eigen values of $\Sigma$, $\lambda_{1}, \lambda_{2}, \ldots ., \lambda_{p}$ are all distinct,

That is

$$
\begin{aligned}
& \lambda_{1}>\lambda_{2}> \\
& \operatorname{Var}(Y)=\operatorname{Var}\left(a_{1} X\right) \\
& =a_{1}^{\prime} \Sigma a_{1} \\
& =a_{1}^{\prime}\left(\delta a_{1}\right)
\end{aligned}
$$$$
>\lambda_{p} \geq 0
$$

Using (14), which is equal to $\delta a_{1}^{\prime} a_{1}=\delta$ will take it largest value at $\delta=\lambda_{1}$, since this is the value of the largest Eigen value, with $a_{1}$ being the Eigen vector corresponding to $\lambda_{1}$.

\section{Results}

The data from the survey were grouped for each of the four characteristics. Occupation was grouped into unemployed, paid employment and self employment. Income was grouped into $0-<\mathrm{N} 10,000, \mathrm{~N} 10,000-<$ N20,000, N20,000 and above. Household size was grouped into small (1-3), moderate (4-7), large (7 and above) and educational level was grouped into primary, secondary and tertiary. S-plus was for the analysis.

The stratification technique in this study divided up the

\begin{tabular}{|c|c|c|c|c|}
\hline Strata & $\begin{array}{l}\text { Educational } \\
\text { Level }\end{array}$ & $\begin{array}{l}\text { Number } \\
\text { Abeokuta } \\
\text { population }\end{array}$ & $\begin{array}{r}\text { in } \\
\text { South }\end{array}$ & $\begin{array}{l}\text { Number in } \\
\text { Ijebu North } \\
\text { population }\end{array}$ \\
\hline 1 & Primary & 53 & & 44 \\
\hline 2 & Secondary & 74 & & 85 \\
\hline \multirow[t]{2}{*}{3} & Tertiary & 73 & & 71 \\
\hline & & 200 & & 200 \\
\hline
\end{tabular}
population into sub-population or strata. The strata for the four characteristics are in Table 1, 2, 3, and 4

Table 1: Stratified Data on Occupation of Heads of Household in both Abeokuta South and Ijebu North

\begin{tabular}{llll}
\hline Strata & Occupation & $\begin{array}{l}\text { Number in } \\
\text { Abeokuta } \\
\text { population }\end{array}$ & $\begin{array}{l}\text { Number in } \\
\text { Ijebu North } \\
\text { population }\end{array}$ \\
\hline 1 & Unemployed & 10 & 2 \\
2 & Paid employment & 47 & 54 \\
3 & Self employment & 143 & 144 \\
& & 200 & 200 \\
\hline
\end{tabular}

Table 2: Stratified Data on Income of Heads of Household in both Abeokuta South and Ijebu North

\begin{tabular}{llll}
\hline Strata & Income N(000) & $\begin{array}{l}\text { Number in } \\
\text { Abeokuta } \\
\text { South } \\
\text { population }\end{array}$ & $\begin{array}{l}\text { Number in } \\
\text { Ijebu North } \\
\text { population }\end{array}$ \\
\hline 1 & 0 to under N10,000 & 42 & 28 \\
2 & N10,000< N20,000 & 73 & 91 \\
3 & N20,000 and over & 85 & 81 \\
& & 200 & 200 \\
\hline
\end{tabular}

Table 3: Stratified Data on Dependant Size of Heads of Household in both Abeokuta South and Ijebu North

\begin{tabular}{llll}
\hline Strata & Dependant Size & $\begin{array}{l}\text { Number in } \\
\text { Abeokuta } \\
\text { population }\end{array}$ & $\begin{array}{l}\text { Number in } \\
\text { Ijebu North } \\
\text { population }\end{array}$ \\
\hline 1 & Small (1 to 3) & 138 & 140 \\
2 & Mrate (4 to 7) & 58 & 55 \\
3 & Large (7 and over) & 4 & 5 \\
& & 200 & 200 \\
\hline
\end{tabular}

Table 4: Stratified Data on Educational Level of Heads of Household in Abeokuta South and Ijebu North 
The merged stratified data for the four socioeconomic characteristics of Abeokuta South and Ijebu North LGAs are shown in Table 5.

Table 5: Stratified Data on Occupation, Income, Dependant Size and Educational Level of Heads of Households in Abeokuta South and Ijebu North

\begin{tabular}{|c|c|c|c|c|}
\hline $\begin{array}{l}\text { Item } \\
\text { No. }\end{array}$ & Name & \multicolumn{2}{|c|}{ Stratum } & $\begin{array}{l}\text { Size of } \\
\text { Stratum } \\
\text { Abeokuta } \\
\text { South and } \\
\text { Ijebu-North }\end{array}$ \\
\hline \multirow{4}{*}{1} & \multirow{3}{*}{ Occupation } & & Unemployed & 12 \\
\hline & & & Paid employment & 101 \\
\hline & & & Self employment & 287 \\
\hline & \multirow{3}{*}{ Income (in $\mathbb{N}^{\prime} 000$ ) } & & $0-10$ & 70 \\
\hline \multirow[t]{3}{*}{2} & & 2 & $10-20$ & 164 \\
\hline & & 3 & $20+$ & 166 \\
\hline & & & Small (1-3) & 278 \\
\hline \multirow[t]{3}{*}{3} & \multirow[t]{3}{*}{ Dependant Size } & 2 & Moderate (4-7) & 113 \\
\hline & & & Large $(7+)$ & 9 \\
\hline & & 1 & Primary & 97 \\
\hline \multirow[t]{2}{*}{4} & \multirow[t]{2}{*}{ Educational Level } & & Secondary & 159 \\
\hline & & & Tertiary & 144 \\
\hline
\end{tabular}

Using the data set for Abeokuta and Ijebu, the general multi-objective optimisation programme as in (8) is $\min \hat{\operatorname{Var}}\left(\bar{y}_{s t}\right)=\min _{n}\left(\begin{array}{l}\hat{\operatorname{Var}}\left(\bar{y}_{s t}^{1}\right) \\ \\ \hat{\operatorname{Var}}\left(\bar{y}_{s t}^{2}\right)\end{array}\right)$

Subject to

$$
\begin{aligned}
& \sum_{h=1}^{4} n_{h}=200 \\
& 2 \leq n_{h} \leq N_{h}, h=1,2,3 \\
& n_{h} \in \mathrm{N}
\end{aligned}
$$

Furthermore, we consider the following two programmes for the non linear minimizing of integers:

$$
\min _{n} \hat{\operatorname{Var}}\left(\bar{y}_{s t}^{1}\right)
$$

Subject to

$$
\begin{aligned}
& \sum_{h=1}^{4} n_{h}=200 \\
& 2 \leq n_{h} \leq N_{h}, h=1,2,3 \\
& n_{h} \in \mathrm{N}
\end{aligned}
$$

and

$$
\min _{n} \hat{\operatorname{Var}}\left(\bar{y}_{s t}^{2}\right)
$$

Subject to

$$
\begin{aligned}
& \sum_{h=1}^{4} n_{h}=200 \\
& 2 \leq n_{h} \leq N_{h}, h=1,2,3 \\
& n_{h} \in \mathrm{N}
\end{aligned}
$$

To extend the idea of this approach, the matrix of variance-covariances of the vector $\bar{y}_{s t}=\left(\bar{y}_{s t}^{1}, \ldots \ldots, \bar{y}_{s t}^{G}\right)^{\prime}$. was computed. The Eigen-values of the covariance matrix of Abeokuta and Ijebu data sets are as shown in Table 6.
Table 6: Eigen-values of the Covariance Matrix of Abeokuta and Ijebu Data Set

\begin{tabular}{lll}
\hline Eigenvalues $\left(\lambda_{i}\right)$ & Abeokuta & Ijebu \\
\hline 1 & 0.7593 & 0.7788 \\
2 & 0.3970 & 0.3391 \\
3 & 0.2297 & 0.2089 \\
4 & 0.1539 & 0.1266 \\
\hline
\end{tabular}

\begin{tabular}{|c|c|c|c|c|}
\hline & Occupation & Income & $\begin{array}{l}\text { Dependant } \\
\text { Size }\end{array}$ & $\begin{array}{l}\text { Educational } \\
\text { Level }\end{array}$ \\
\hline Occupation & 0.2361 & -0.0272 & -0.0391 & -0.1333 \\
\hline Income & -0.0272 & 0.2924 & 0.0677 & 0.2052 \\
\hline $\begin{array}{l}\text { Dependant } \\
\text { Size }\end{array}$ & -0.0391 & 0.0677 & 0.4046 & 0.0447 \\
\hline $\begin{array}{l}\text { Educational } \\
\text { Level }\end{array}$ & -0.1333 & 0.2052 & 0.0447 & 0.6068 \\
\hline
\end{tabular}

The summary estimates of the sample statistics for Abeokuta South and Ijebu North samples are as shown in Tables 7 and 8

Table 7: Summary Estimates of Abeokuta South Sample Statistics

\begin{tabular}{lll}
\hline & Income & Dependant Size \\
\hline $\operatorname{Mean}\left(\bar{y}_{s t}\right)$ & 2.067 & 1.3000 \\
$\mathrm{~V}_{\text {srs }}(\bar{y})$ & 0.0214 & 0.0062 \\
$\operatorname{Var}(\operatorname{post})$ & 0.0073 & 0.0036 \\
$\mathrm{~V}_{\text {mod }}\left(\bar{y}_{s t}\right)$ & 0.0045 & 0.0023 \\
\hline
\end{tabular}

Table 8: Summary Estimates of Ijebu North Sample Statistics

\begin{tabular}{lll}
\hline & Income & Dependant Size \\
\hline $\operatorname{Mean}\left(\bar{y}_{s t}\right)$ & 2.033 & 1.333 \\
$\mathrm{~V}_{\text {srs }}(\bar{y})$ & 0.0206 & 0.0016 \\
$\operatorname{Var}(\operatorname{post})$ & 0.0067 & 0.0014 \\
$\mathrm{~V}_{\text {mod }}\left(\bar{y}_{s t}\right)$ & 0.0038 & 0.0011 \\
\hline
\end{tabular}

The variance-covariance matrix for Abeokuta and Ijebu data sets are shown in tables 9 and 10 respectively

Table 9: Variance-Covariance Matrix of Abeokuta Data Set

Table 10: Variance-Covariance Matrix of Ijebu Data Set

\begin{tabular}{lllll}
\hline & Occupation & Income & $\begin{array}{l}\text { Dependant } \\
\text { Size }\end{array}$ & $\begin{array}{l}\text { Educational } \\
\text { Level }\end{array}$ \\
\hline Occupation & 0.2197 & -0.0508 & -0.0392 & -0.1744 \\
$\begin{array}{l}\text { Income } \\
\begin{array}{l}\text { Dependant } \\
\text { Size }\end{array}\end{array}$ & -0.0508 & 0.3020 & 0.0761 & 0.2132 \\
$\begin{array}{l}\text { Educational } \\
\text { Level }\end{array}$ & -0.1744 & 0.2132 & 0.1059 & 0.5484 \\
\hline
\end{tabular}

The principal component analysis ensured that the variance-covariance matrix was decomposed and the eigenvalues and eigenvectors calculated from the multivariate data representing information from the households. The principal component on the basis of the sample covariance matrix for the merged sample data sets for Abeokuta South and Ijebu North are: 


$$
\begin{aligned}
& Y_{1}=-0.283 X_{1}+0.428 X_{2}+0.278 X_{3}+0.812 X_{4} \\
& Y_{2}=-0.069 X_{1}-0.0169 X_{2}-0.948 X_{3}+0.309 X_{4} \\
& Y_{3}=-0.667 X_{1}-0.729 X_{2}-0.010 X_{3}+0.118 X_{4} \\
& Y_{4}=-0.686 X_{1}+0.534 X_{2}-0,116 X_{3}-0.481 X_{4}
\end{aligned}
$$

with corresponding sample variance $0.7788,0.3391,0.2089$ and 0.1266 respectively. The total variance is 1.4534 and the principal components $\vec{Y}_{1}, \vec{Y}_{2}, \vec{Y}_{3}, \vec{Y}_{4}$

accounts for $53,6 \%, 23.3 \%, 14.4 \%$ and $8.7 \%$ of the total variance. Similarly, the principal components based on the merged sample correlation matrix are given by

$$
\begin{aligned}
& \widetilde{Y}_{1}=1.000 X_{1}-0.151 X_{2}-0.131 X_{3}-0.425 X_{4} \\
& \widetilde{Y}_{2}=-0.151 X_{1}+1.000 X_{2}+0.211 X_{3}+0.505 X_{4} \\
& \widetilde{Y}_{3}=-0.131 X_{1}+0.211 X_{2}+1.000 X_{3}+0.158 X_{4} \\
& \widetilde{Y}_{4}=-0.425 X_{1}+0.505 X_{2}+0.158 X_{3}+1.000 X_{4}
\end{aligned}
$$

The sample variance of the new principal components $\vec{Y}_{1}, \vec{Y}_{2}, \vec{Y}_{3}, \vec{Y}_{4}$

are $1.8381,0.9244,0.8323$ and 0.4052 respectively while the total variance is 4 . The principal components account for $44.6 \%, 23.1 \%, 20.8 \%$ and $10.1 \%$ of the total variance. Using the Eigen function, Eigen values of the merged sample covariance matrix were $0.76516,0.36722,0.21742$ and 0.14319 with standard deviations $0.8747,0.6060$, 0.4663 and 0.3784 respectively.

\section{Conclusion}

In this study, optimal allocation in multi-item is developed as a multivariate optimization problem by finding the principal components. This was done by determining the overall linear combinations that concentrates the variability into few variables.

From the principal component analysis, it was seen that for both Abeokuta and Ijebu data sets, the variance based on the four characteristics as multivariate is less than that of the variables when considered as a univariate. From the results, it was seen that there was no difference in the percentage of the total variance accounted for by the different components from the merged sample when compared with the individual sample. Optimum allocation was achieved when there was stratification.

\section{References}

[1] Bankier, M. D. 1996. Estimators based on several stratified samples with applications to multiple frame survey. Journal of American Stat. Assoc. 81: 1074 - 1079.

[2] Cheang, C. 2011. Sampling strategies and their advantages and disadvantages. http://www.2.hawaii.edu/ cheang/Sampling\%20Strategies\% 20Advantages\%20and\%20Disadvantages.htm (Accessed March 5, 2011).

[3] Cochran, W. G. 1977. Sampling Techniques ( ${ }^{\text {rd }}$ Edition), New York, Wiley.

[4] Diaz-Garcia, J.A and Ramos-Quiroga, R. 2011. Multivariate Stratified Sampling by Stochastic Multi Objective Optimization. Xiv: 1106.0773VI. Statistical Methodology. $X I V, 1116-1123$.

[5] Diaz-Garcia, J. A. and Cortez, L. U. 2006. Optimum allocation in multivariate stratified sampling: multiobjective programming. Communicacion Technica: Communicaciones Del CIMAT. 6(7), 28-33.

[6] Hartley, H. O. 1962. Multiple frame surveys: Proceeding of the social statistics section of American Statistical Association, $205-215$.

[7] Hartley, H. O. 1964. A new estimation theory for sampling surveys. Biometrics, 55, $545-557$.

[8] Khan, M.G.M and Ahsan, M.J. 2003. A note on Optimum Allocation in Multivariate Stratified Sampling. South Pacific Journal Natural Science, 21, 91-95.

[9] Kokan, A.R and Khan, S.U., 1967. Optimum allocation in mutivariate surveys. An analytical solution. Journal of Royal Statistical Society. Series B, 29, 115-125.

[10] Lumley, T. 2004. Analysis of complex survey samples. Department of Biostatistics. University of Washington Press.

[11] Miettinen, K. M. 1999. Non linear multi-objective optimization. Kluwer Academic Publishers, Boston.

[12] Pirzada, S. and Maqbool, S. 2003. Optimal Allocation in Multivariate sampling Through Chebyshev's Approximation. Bulletin of the Malaysian Mathematical Science Society, 2, (26), $221-230$.

[13] Saxens, J., Narain, M. U. and Srivastava, S. 1986. The maximum likelihood method for non-response in Surveys. Survey Methodology. 12, $50-62$.

[14] Sethna, B. N. and Groeneveld, L. 1984. Research Methods in Marketing and Management. Tata, Mcgraw-Hill, publishing, New-Delhi.

[15] Steuer, R.E. 1986. Multiple criteria optimization: Theory, Computation and applications. John Wiley, New York.

[16] Winship, C. and Radbill, L. 1994. Sampling weights and regression analysis. Sociological Methods and Research, 23, (2), $230-257$. 